\title{
Razpad partnerske zveze na prehodu v odraslost: Spoprijemanje s stresom kot napovednik posttravmatske rasti
}

\author{
Simona Zgaga ${ }^{1}$ in Andreja Avsec ${ }^{* 2}$ \\ ${ }^{1}$ Medvode, Slovenija \\ ${ }^{2}$ Oddelek za psihologijo, Filozofska fakulteta, Univerza v Ljubljani
}

\begin{abstract}
Povzetek: V obdobju prehoda v odraslost je razpad partnerske zveze relativno pogost dogodek, vendar je izguba partnerja prav tako stresna in čustveno obremenjujoča kot $v$ kasnejših razvojnih obdobjih. V raziskavi nas je zanimala povezanost posttravmatske rasti z načini spoprijemanja s stresom pri 260 posameznikih na prehodu v odraslost, ki so doživeli razpad heteroseksualne partnerske zveze do dve leti pred sodelovanjem v raziskavi. Udeleženci so izpolnili Vprašalnik posttravmatske rasti PTGI, Vprašalnik spoprijemanja s stresom COPE, Vprašalnik na čustva usmerjenega spoprijemanja EAC in Vprašalnik spoprijemanja s stresom po razpadu partnerske zveze, ki smo ga oblikovali za namene te raziskave. Ob nadzorovanju spola in starosti načini spoprijemanja s stresom pojasnijo $34 \%$ variabilnosti med posamezniki v posttravmatski rasti. Pomembni napovedniki posttravmatske rasti so načini spoprijemanja, ki so usmerjeni na problem, načini, ki so usmerjeni na čustva in na druge ljudi, načini, ki se nanašajo na sprejetje situacije in pozitivno samomotiviranje ter načini, ki omogočajo distanciranje od stresorja. Z rastjo so torej povezani tako načini, ki so usmerjeni na problem, kot tudi nekateri načini, ki so usmerjeni na čustva, kar je razumljivo, saj je razpad zveze stresor, ki ga posameznik naknadno ne more odstraniti, lahko se predvsem bolj ali manj uspešno spoprijema z negativnimi čustvi, ki so posledica tega stresorja.
\end{abstract}

Ključne besede: prekinitev partnerske zveze, spoprijemanje, posttravmatska rast

\section{Relationship termination in emerging adulthood: Coping strategies as predictors of posttraumatic growth}

\author{
Simona $\mathrm{Zgaga}^{1}$ and Andreja Avsec ${ }^{2}$ \\ ${ }^{1}$ Medvode, Slovenia \\ ${ }^{2}$ Department of Psychology, Faculty of Arts, University of Ljubljana, Slovenia
}

\begin{abstract}
Relationship termination happens relatively often in emerging adulthood but is nevertheless as distressing then as it is later in life. We examined the relationship between coping strategies and posttraumatic growth in a sample of 260 emerging adults whose heterosexual romantic relationships were terminated at most two years before participating in the study. Participants completed The Posttraumatic Growth Inventory, The COPE Inventory and Emotion Approach Coping scale. For the purposes of the study we also conceptualized a new coping inventory, related specifically to coping with relationship termination. While controlling for gender and age the coping strategies explained $34 \%$ of variability in posttraumatic growth. Statistically significant predictors of posttraumatic growth were problem-oriented coping strategies, coping strategies, oriented towards emotions and other people, acceptance and positive self-motivation as well as coping strategies that allow some distancing from the stressor. Results indicate that posttraumatic growth is related to problem-oriented and also to emotion-oriented coping strategies, which is reasonable since relationship termination is a stressor that cannot be eliminated. It is important that an individual who is facing it can cope well with the unpleasant emotions deriving from relationship termination.
\end{abstract}

Key words: relationship termination, posttraumatic growth, coping behaviour

\footnotetext{
${ }^{*}$ Naslov/Address: Andreja Avsec, Oddelek za psihologijo, Filozofska fakulteta, Univerza v Ljubljani, Aškerčeva 2, 1000 Ljubljana, e-mail: andreja.avsec@ff.uni-lj.si
}

Članek je licenciran pod pogoji Creative Commons Attribution 4.0 licence. / The article is licensed under a Creative Commons Attribution 4.0 International License. 
Oblikovanje intimnega, stabilnega in relativno trajnega partnerskega odnosa je ena od pomembnejših razvojnih nalog obdobja prehoda v odraslost (Zupančič, 2004). Uspešno obvladovanje te razvojne naloge je zato pomemben dejavnik subjektivnega zadovoljstva ter odobravanja okolice. Ker se posamezniki na prehodu v odraslost v intimnosti še preizkušajo (Arnett, 2000), so razpadi partnerskih zvez v tem obdobju pogosti. Rhoades, Kamp Dush, Atkins, Stanley in Markman (2011) na primer poročajo, da je v obdobju 20 mesecev razpadlo kar $36,5 \%$ zvez neporočenih udeležencev, starih med 18 in 35 let. Posledice razpada partnerske zveze so močno odvisne od načinov spoprijemanja s stresom. Večina predhodnih raziskav na tem področju se je osredotočala na negativne posledice stresorjev in na vlogo načinov spoprijemanja $s$ stresom za ublažitev teh negativnih posledic (Folkman in Moskowitz, 2004). Konstrukt posttravmatske rasti predstavlja nov pogled na posledice doživljanja nekega stresnega dogodka, saj predvideva možnost pozitivnih sprememb pri posamezniku kljub močnim negativnim posledicam.

\section{Negativne posledice razpada partnerske zveze}

Razpad partnerske zveze je za večino posameznikov, ki ga doživi, zelo stresen. Potrebe, ki jih sicer zadovoljijo v zvezi, npr. partnerjeva družba, skupna rutina, intimnost, čustvena vpletenost in drugo (Drigotas in Rusbult, 1992), ostanejo nezadovoljene. Posameznik lahko utrpi tudi izgubo tistega dela socialne mreže, ki je bil bolj povezan z bivšim partnerjem (Hebert, 2006), onemogočena pa je tudi uresničitev skupnih načrtov za prihodnost (Simpson, 1987). Zaradi vsega naštetega ni presenetljivo, da je razpad partnerske zveze pomemben napovednik prve depresivne epizode $\mathrm{v}$ mladostništvu (Monroe, Rohde, Seeley in Lewinsohn, 1999), z depresivnimi simptomi pa je povezan tudi pri starejših posameznikih (Simon in Barrett, 2010). Težave v partnerskih odnosih so tudi med najpogostejšimi razlogi, da študenti poiščejo pomoč $\mathrm{v}$ univerzitetnih svetovalnicah (Benton, Robertson, Tseng, Newton in Benton, 2003). Po razpadu romantične zveze so posamezniki na splošno manj zadovoljni z življenjem kot pred razpadom, čutijo več psihološkega distresa (Rhoades idr., 2011), lahko imajo tudi slabšo samopodobo, občutek nižjega samospoštovanja ter osebnega poraza in neustreznosti (Perriloux in Buss, 2008; Tashiro in Frazier, 2003; Tashiro, Frazier in Berman, 2006).

\section{Spoprijemanje s stresom po razpadu partnerske zveze}

Raziskav, ki bi poročale o pogostosti uporabe določenih načinov spoprijemanja s stresom po razpadu partnerske zveze, je malo. Večinoma so avtorji proučevali prisotnost različnih vrst vedenja, s katerimi posamezniki skušajo blažiti negativne posledice razpada partnerske zveze. Teh vedenj pa ne moremo vedno uvrstiti med načine spoprijemanja s stresom, ki jih ocenjujejo uveljavljeni vprašalniki. Udeleženci raziskave avtorjev Perillouxa in Bussa (2008) so po razpadu zveze najpogosteje poročali o vedenjih, kot so pogovor o razhodu, razkrivanje žalosti, ruminacija in izogibanje bivšemu partnerju. Redkeje so poročali o vedenjih, kot so grožnje ali nasilje nad bivšim partnerjem, grožnje s samomorom in raba drog. V podobni raziskavi (Choo, Levine in Hatfield, 1996) avtorji navajajo, da so udeleženci v primeru razpada partnerske zveze poročali o poskusih odvračanja pozornosti (zaposliti se $\mathrm{z}$ delom, izobraževanjem, kariero; vključevanje $\mathrm{V}$ športne aktivnosti), sledila so vedenja samoobtoževanja (ugotavljanje, kaj posameznik storil narobe; kaj bi lahko naredil, da bi rešil partnersko zvezo) in obtoževanja partnerja (razmišljanje, kako grdo je partner ravnal $\mathrm{z}$ njim/njo), najredkeje pa so poročali o rabi alkohola in drog. Tamres, Janicki in Helgeson (2002) so z meta-analizo ugotovili, da je pri stresorjih, ki so povezani s težavami v odnosih, torej ne nujno samo pri razpadu partnerske zveze, malo razlik med moškimi in ženskami. Ker naj bi se moškim zdeli problemi, ki vključujejo druge ljudi, neobvladljivi in izven njihovega nadzora, se pogosteje kot ženske skušajo izogniti soočenju s problemom. Ženske pa se tudi po razpadu partnerske zveze pogosteje kot moški naslanjajo na svojo socialno mrežo in pogosteje iščejo ter tudi dobijo socialno oporo pri bližnjih (Graff-Reed, 2004). Moški v situaciji razpada partnerske zveze iščejo manj socialne opore (Tamres idr., 2002), vendar to ne pomeni, da moški ob razhodu čutijo manj bolečine. Wyder, Ward in De Leo (2009) na podlagi svoje raziskave na primer poročajo, da je razpad partnerske zveze pomembno povezan $s$ tveganjem za samomor predvsem pri mlajših moških.

\section{Posttravmatska rast}

Stresni in travmatski dogodki puščajo na posameznikih različne negativne fizične in psihične posledice. Posamezniki poročajo o občutjih anksioznosti, strahu, žalosti, depresivnem razpoloženju, krivdi, jezi, razdražljivosti, včasih so prisotni tudi nefunkcionalni miselni vzorci, npr. zanikanje ali vsiljive misli, neprijetne fizične reakcije (utrujenost, glavobol, težave $\mathrm{z}$ želodcem in podobno), možna posledica pa so lahko tudi posttravmatska stresna motnja, depresivne ali anksiozne motnje in drugo (Tedeschi in Calhoun, 2004). Ob vseh negativnih posledicah pa nekateri posamezniki po stresnih ali travmatskih dogodkih poročajo tudi o pozitivnih posledicah. Avtorji (pregled v Linley in Joseph, 2009) različno poimenujejo zaznavanje pozitivnih posledic po stresnih in travmatskih dogodkih, npr. s stresom povezana rast, pozitivne spremembe, pozitivna adaptacija, prepoznavanje koristi, v nadaljevanju pa bosta uporabljeni bodisi besedna zveza zaznane pozitivne spremembe bodisi posttravmatska rast (Tedeschi in Calhoun, 1996).

Posttravmatska rast se nanaša na posameznikovo doživljanje pomembnih pozitivnih psiholoških sprememb, ki sledijo zahtevnim stresnim življenjskim okoliščinam ali travmatskim dogodkom (Calhoun, Cann, Tedeschi in McMillan, 2000; Linley in Joseph, 2009). Tedeschi 
in Calhoun (2004) poudarjata, da se posttravmatska rast nanaša na spremembe pri posameznih, ki presegajo zmožnost upiranja oškodovanosti zaradi stresnega dogodka. Ne gre torej zgolj za prožnost, saj se ta nanaša na stabilnost delovanja $\mathrm{v}$ težavnih obdobjih, ampak za nenormativen pozitiven preskok $\mathrm{v}$ posameznikovem doživljanju in delovanju (Linley in Joseph, 2009).

Koncept posttravmatske rasti se nanaša na pozitivne spremembe na treh širših področjih (Linley in Joseph, 2009; Tedeschi in Calhoun, 1996). Pozitivne spremembe na področju zaznavanja sebe se nanašajo na večje zavedanje osebne moči, višjo samozavest in odpornost na težave, pogosto z bolj jasnim zavedanjem lastne ranljivosti in omejitev. Posamezniki v takih primerih poročajo, da se bolj zanesejo nase in da bolje obvladujejo stresne situacije, da zmorejo več, kot so pričakovali, prepoznavajo nove priložnosti ter na splošno poročajo o »čustveni rasti« in o občutku, da so »boljši ljudje«. Drugo pomembno področje, kjer se lahko pojavijo spremembe, so medosebni odnosi. Tukaj se spremembe kažejo kot povečano sočutje do drugih, altruizem, intenzivnejše zaznavanje intimnosti v odnosih z drugimi (z družino, s prijatelji). Posamezniki poročajo, da bolj cenijo prijateljstva in da vnašajo več truda v poglobitev odnosov, npr. z družinskimi člani, od katerih so se prej čutili odtujene. Tretje področje pozitivnih sprememb pa je življenjska filozofija. Posamezniki po travmatskem dogodku bolj cenijo svoj obstoj, vse, kar še imajo (česar oz. kogar niso izgubili), bolj uživajo v vsakem dnevu, reči več ne jemljejo za samoumevne in skušajo izkoristiti vsak trenutek; možne so tudi spremembe v duhovnosti ter verskih in eksistencialnih prepričanjih. Posamezniki lahko poročajo o spremembi prioritet $\mathrm{v}$ življenju in jasnejšem zavedanju minljivosti.

\section{Načini spoprijemanja z razpadom zveze in posttravmatska rast}

Razpad zveze se od večine stresnih ali travmatskih dogodkov, na katerih so doslej preučevali posttravmatsko rast (npr. naravne katastrofe, terorizem, biti žrtev ali priča zločina, bolezni - obsežen pregled $\mathrm{v}$ Joseph in Linley, 2008) razlikuje po tem, da stopnja stresnosti ni tako visoka, vendar gre za pogost stresor, saj se $\mathrm{z}$ njim v življenju sreča večina ljudi, mnogi od njih celo več kot enkrat (Tashiro in Frazier, 2003). Več kot 85 \% odraslih Američanov je poročalo o razpadu vsaj ene romantične zveze (Battaglia, Richard, Datteri in Lord, 1998). Ker lahko posttravmatska rast po razpadu partnerske zveze vpliva na kvaliteto naslednjih partnerskih zvez, je torej smiselno ugotoviti, kaj spodbudi pozitivne spremembe po razpadu partnerske zveze.

Le malo raziskovalcev je do sedaj empirično preučevalo, ali so določeni načini spoprijemanja povezani s posttravmatsko rastjo oziroma ali lahko določeni načini spoprijemanja bolj verjetno vodijo $\mathrm{k}$ posttravmatski rasti. Avtorji ugotavljajo, da se na problem usmerjeni načini pozitivno povezujejo $\mathrm{z}$ doživljanjem pozitivnih izidov po stresnem dogodku, izogibanje pa se $\mathrm{z}$ rastjo ne povezuje (Dolbier, Smith Jaggars in Steinhardt, 2010).
Socialna opora, tako čustvena kot instrumentalna, je bila s posttravmatsko rastjo pomembno povezana na vzorcu bolnikov z rakom (Morris, Shakespeare-Finch in Scott, 2007). Tako aktivno spoprijemanje kot socialna opora sta bili pomembno povezani s posttravmatsko rastjo tudi pri otrocih in mladostnikih, žrtvah hurikana Katrina (Schexnaildre, 2011).

Lewandowski in Bizocco (2007) sta avtorja raziskave, $\mathrm{v}$ kateri sta preučevala povezanost spoprijemanja $\mathrm{s}$ stresom po razpadu partnerske zveze s posttravmatsko rastjo. Vključila sta le nekaj podlestvic vprašalnika COPE (Carver, Scheier in Weintraub, 1989). Z rastjo po razpadu zveze so bili pomembno pozitivno povezani načini spoprijemanja pozitivna reinterpretacija in rast, iskanje čustvene socialne opore ter sprejetje. Načini spoprijemanja s stresom iskanje instrumentalne socialne opore, usmerjenost na sproščanje čustev, zanikanje in miselna neaktivnost pa $\mathrm{v}$ njihovi raziskavi niso bili pomembno povezani $\mathrm{s}$ posttravmatsko rastjo. Da je za posttravmatsko rast po razpadu partnerske zveze pomembna socialna opora, pa je pokazala tudi raziskava R. Graff-Reed (2004).

V zvezi $\mathrm{z}$ razlikami med spoloma $\mathrm{V}$ doživljanju posttravmatske rasti raziskave dokaj enoznačno ugotavljajo, da ženske $\mathrm{v}$ primerjavi z moškimi poročajo o večji zaznani posttravmatski rasti, posebej na področju odnosov z drugimi, in to tako v splošnem (Tedeschi in Calhoun, 1996) kot tudi po razpadu zveze (Tashiro in Frazier, 2003). Razliko avtorji pripisujejo predvsem temu, da se ženske pogosteje kot moški $\mathrm{z}$ razpadom spoprijemajo tako, da poiščejo socialno oporo (Tamres idr., 2002), kar podpira posttravmatsko rast (Graff-Reed, 2004). Pomembno je omeniti, da dobivajo ženske socialno oporo tudi zunaj partnerske zveze, pri družini in prijateljih, moški pa se večinoma zaupajo le svojim partnerkam (Reevey, 2007). Po razpadu zveze, ko partnerke kot vira opore ni več, med prijatelji pa moški nimajo toliko zaupnikov, je torej njihova priložnost za rast ob pomoči opornega sistema pomembnih drugih omejena.

\section{Namen raziskave}

$\mathrm{V}$ raziskavi nas je zanimala povezanost med načini spoprijemanja s stresom in posttravmatsko rastjo. Veliko dosedanjih raziskav kaže na osrednji pomen spoprijemanja s stresom za čim manjše negativne posledice stresorjev, ki jih doživlja posameznik (Folkman in Moskowitz, 2004). $\mathrm{V}$ nasprotju $\mathrm{z}$ dosedanjimi raziskavami pa vključitev konstrukta posttravmatske rasti omogoča tudi proučevanje možnih pozitivnih posledic zelo negativnih stresnih situacij. Predvidevamo, da bodo načini spoprijemanja $\mathrm{z}$ razpadom partnerske zveze pojasnili pomemben delež variabilnosti v posttravmatski rasti, pri čemer naj bi bili bolj učinkoviti oz. konstruktivni načini spoprijemanja $\mathrm{s}$ stresom bolj verjetno povezani s posttravmatsko rastjo. Kljub temu, da na problem usmerjeni načini spoprijemanja načeloma predstavljajo najbolj konstruktivne načine spoprijemanja, je treba v naši raziskavi upoštevati, da so udeleženci ocenjevali svoje vedenje $\mathrm{v}$ zvezi $\mathrm{z}$ razpadom 
partnerske zveze, torej za stresor, ki ga posamezniki primarno ocenjujejo kot škodo, ki je že bila povzročena (Lazarus in Folkman, 1984). Pri takih stresorjih pa je bolj verjetna in tudi smiselna uporaba načinov spoprijemanja, usmerjenih na čustva, zatorej ni nujno, da so v situaciji razpada partnerske zveze konstruktivni samo na problem usmerjeni načini spoprijemanja. Ker avtorji vprašalnika načinov spoprijemanja (Carver idr., 1989), ki smo ga uporabili v naši raziskavi, zavračajo vnaprejšnje grupiranje načinov spoprijemanja, pač pa predlagajo, da se to naredi na vsakem vzorcu posebej, smo tudi v naši raziskavi najprej grupirali načine spoprijemanja s stresom v nekaj manjših skupin.

Pričakovali smo pozitivno povezanost načina spoprijemanja pozitivna reinterpretacija in rast $\mathrm{S}$ posttravmatsko rastjo, saj sta si konstrukta vsebinsko najbližja: oba se namreč nanašata na prepoznavanje pozitivnih vidikov stresne situacije ali njenih izidov. Lewandowski in Bizzoco (2007) sta pozitivne povezave med rastjo in pozitivno reinterpretacijo in rastjo kot načinom spoprijemanja tudi empirično potrdila. Nadalje smo predvidevali, da se bodo s posttravmatsko rastjo pozitivno povezovali načini spoprijemanja, usmerjeni na problem, saj predstavljajo najbolj konstruktivne načine spoprijemanja s stresom, ko z načrtovanjem in aktivnostjo nekaj naredimo $\mathrm{v}$ zvezi s stresorjem. Tudi predhodne raziskave kažejo, da je posttravmatska rast največja, ko posamezniki uporabljajo aktivne načine spoprijemanja (Dolbier idr., 2010; Schexnaildre, 2011).

Predvidevali smo tudi, da se bodo s posttravmatsko rastjo pozitivno povezovali na čustva usmerjeni načini spoprijemanja. Čeprav se načinov, usmerjenih na čustva, drži »slab sloves« nekonstruktivnosti (Austenfeld in Stanton, 2004), že od kar sta Lazarus in S. Folkman (1984) razdelila načine spoprijemanja na tiste, usmerjene na problem, in tiste, usmerjene na čustva, pa lahko namerna usmeritev na čustva, na njihovo izražanje in razmišljanje o njih predstavlja zelo konstruktiven način spoprijemanja (Austenfeld in Stanton, 2004). Čustva imajo v svoji osnovi prilagoditveno funkcijo (npr. Plutchik, 2002), zato lahko namensko in aktivno spoprijemanje preko predelovanja in izražanja čustev vodi $\mathrm{k}$ pozitivnim izidom. $\mathrm{V}$ primeru razpada zveze, ko je škoda že bila povzročena in $\mathrm{v}$ bistvu stresorja ne moremo odstraniti oz. nanj delovati, pa je še toliko bolj smiselno zavestno usmeriti se na doživljanje in analiziranje teh čustev. Sprejetje svojih čustev ob tako stresnem dogodku, razmišljanje o njih in njihovo izražanje je predpogoj, da lahko pride do drugačnega pogleda na stresni dogodek ter da posameznik začne zaznavati pozitivne spremembe kot posledico tega dogodka.

Predvidevali smo tudi, da se bodo s posttravmatsko rastjo pomembno pozitivno povezovali socialno podprti načini spoprijemanja. Pomembni drugi lahko podprejo posameznika pri njegovih poskusih mišljenjske in čustvene predelave, iskanja pomena stresnega dogodka ter osmišljanju čustev, ki spremljajo razpad zveze, mu nudijo nov pogled na problem in okrepijo občutek, da je vreden pomoči. Posledica kvalitetnejše predelave stresnega dogodka in zaznane opore pa je lahko višja posttravmatska rast. Tudi dosedanje raziskave kažejo na pozitivne povezave med posttravmatsko rastjo in socialno oporo (npr. Lewandowski in Bizzoco, 2007).

\section{Metoda}

\section{Udeleženci}

$\mathrm{V}$ raziskavi je sodelovalo 260 posameznikov (72,3 $\%$ žensk), starih med 18 in 30 let $(M=22,3$ leta; $S D=$ 2,5 leta), ki so se $z$ nasprotno-spolnim partnerjem razšli v zadnjih dveh letih. Povprečno obdobje med razpadom partnerske zveze in izpolnjevanjem vprašalnikov je bilo 10,5 meseca $(S D=8,0$ mesecev). Zveze udeležencev so pred razpadom trajale od 1 meseca do 96 mesecev $(M=$ 26,5 meseca; $S D=22,0$ meseca). 73,1 \% udeležencev je bilo v času izpolnjevanja vprašalnika samskih, preostali pa $\mathrm{v}$ novi partnerski zvezi, nihče od njih ni bil poročen. Razpad zveze se je po poročanju udeležencev zgodil na njihovo pobudo v 40,4\% primerov, 35,4\% oseb v vzorcu je bilo zapuščenih s strani partnerja, 23,5 \% pa jih poroča, da je bila odločitev o prekinitvi zveze skupna oz. sporazumna. Dva posameznika $(0,8 \%)$ sta poročala, da je bila zveza prekinjena zaradi vplivov okolice. Za 34,2 $\%$ udeležencev je bila partnerska zveza, katere razpad so opisovali, prva, za preostale pa ne.

\section{Pripomočki}

Vprašalnik posttravmatske rasti PTGI (Posttraumatic growth inventory; Tedeschi in Calhoun, 1996) je namenjen merjenju pozitivnih izidov, o katerih poročajo posamezniki po doživeti stresni ali travmatski izkušnji. 21 postavk vprašalnika se združuje v naslednjih pet lestvic: povezanost $\mathrm{z}$ drugimi, nove možnosti, osebna moč, duhovna sprememba in vrednotenje življenja. Udeleženci so vsako postavko ocenili na 4-stopenjski lestvici od $» 0$ $=$ Sploh nisem doživel/a te spremembe zaradi razpada zveze « do »3 = Zelo močno sem doživel/a to spremembo zaradi razpada zveze«. Stopnje na lestvici so bile prirejene za razpad partnerske zveze. Avtorji poročajo o dobrih merskih značilnostih vprašalnika (Tedeschi in Calhoun, 1996). Kljub temu, da avtorji predvidevajo, da je posttravmatska rast večdimenzionalni konstrukt, uporabljajo tudi skupni rezultat vseh lestvic, za kar smo se odločili tudi v naši raziskavi, saj komponentna faktorska analiza postavk vprašalnika na naših podatkih kaže na en močan faktor (lastne vrednosti in pripadajoči deleži pojasnjene variance za prvih pet komponent so naslednje: 8,23 (39\%); 1,7 (8\%); 1,1 (5\%); 1,1 (5\%); 0,96 (5 \%)). Koeficient notranje konsistentnosti $\alpha$ je za vsoto vseh petih lestvic na našem vzorcu znašal 0,92 . Vprašalnik sva iz angleščine $\mathrm{v}$ slovenščino neodvisno prevedli avtorici članka, oblikovali skupni prevod, nato je Sylvia Valentine, naravna govorka angleščine in slovenščine, skupni slovenski prevod prevedla nazaj v angleščino. Vzvratni prevod postavk se vsebinsko ni razlikoval od originalnih postavk. 
Vprašalnik spoprijemanja COPE (The COPE inventory; Carver idr., 1989) meri različne načine spoprijemanja $\mathrm{S}$ stresom. Vprašalnik sestavlja 15 podlestvic s po 4 postavkami: aktivno spoprijemanje, načrtovanje, prekinitev preostalih dejavnosti, zadrževanje spontanega odziva, iskanje instrumentalne socialne opore, iskanje čustvene socialne opore, usmerjenost na sprostitev čustev, vedenjska neaktivnost, miselna neaktivnost, pozitivna reinterpretacija in rast, zanikanje, sprejetje, usmerjenost v vero, uporaba drog in humor. Iz nadaljnje analize je bila izločena lestvica usmerjenosti v vero, saj ni razlikovala med posamezniki (več kot 70 \% udeležencev je doseglo najnižje možno število točk). Avtorji poročajo o sprejemljivih merskih značilnostih (Carver idr., 1989). Koeficienti notranje konsistentnosti $\alpha$ posameznih lestvic na našem vzorcu se gibljejo med 0,62 in 0,95 , kar je primerljivo s koeficienti, o katerih poročajo avtorji; izjema sta lestvici miselna neaktivnost $(\alpha=0,39)$ in vedenjska neaktivnost $(\alpha=0,50)$, katerih zanesljivosti sta povsem nezadovoljivi. V raziskavi so udeleženci ocenili, kako pogosto so uporabljali določen način spoprijemanja v obdobju prvega meseca po razpadu partnerske zveze na 4-stopenjski lestvici od $» 1=$ Tega nisem delal/a« do »4 = To sem delal/a pogosto«. Vprašalnik sta iz angleščine $\mathrm{v}$ slovenščino neodvisno prevedli dve psihologinji in oblikovali skupni prevod, vzvratni prevod pa ni bil opravljen.

Vprašalnik na čustva usmerjenega spoprijemanja EAC (Emotion Approach Coping scale; Stanton, Kirk, Cameron in Danoff-Burg, 2000) meri pogostost rabe dveh načinov spoprijemanja s stresom: predelovanje čustev se nanaša na aktivne in namenske poskuse zaznati in razumeti svoja čustva (npr. Vzel/a sem si čas, da ugotovim, kaj v resnici čutim), izražanje čustev pa na izražanje čustev (npr. Vzel/a sem si čas, da sem lahko izrazil/a svoja čustva). Vsaka lestvica je sestavljena iz štirih postavk. Za vsako postavko so udeleženci ocenili, kako pogosto so se tako vedli v prvem mesecu po razpadu zveze na 4-stopenjski lestvico od $» 1=$ Tega nisem delal/a $\ll$ do $» 4=$ To sem delal/ a pogosto«. Koeficienta notranje konsistentnosti $\alpha$ za naš vzorec znašata 0,79 za lestvico predelovanja čustev in 0,84 za lestvico izražanja čustev. Vprašalnik sta iz angleščine V slovenščino neodvisno prevedli dve psihologinji, oblikovali skupni prevod, nato je prof. anglistike skupni slovenski prevod prevedla nazaj $\mathrm{v}$ angleščino. Vzvratni prevod postavk se vsebinsko ni razlikoval od originalnih postavk.

Vprašalnik spoprijemanja s stresom po razpadu partnerske zveze je vprašalnik, oblikovan za namene te raziskave, saj že omenjena vprašalnika načinov spoprijemanja s stresom ne vključujeta nekaterih načinov spoprijemanja, pogostih po razpadu partnerske zveze. Po pregledu spletnih strani s poljudnimi nasveti o spoprijemanju z razpadom partnerske zveze je bil oblikovan seznam 31 postavk, ki so se nanašale na 7 različnih načinov spoprijemanja $\mathrm{z}$ razpadom zveze (impulzivno iskanje novih partnerjev; samoobtoževanje; prepričevanje partnerja; izogibanje vsemu, kar je povezano $\mathrm{z}$ bivšim partnerjem; razvajanje sebe; maščevanje in oteževanje življenja bivšemu partnerju; ruminacija). Ti naj bi se pojavljali pri posameznikih po razpadu partnerske zveze in naj bi spoprijemanje $\mathrm{z}$ razpadom zveze bodisi olajševali ali pa oteževali. Udeleženci so ocenili pogostost posameznega načina soočenja na 4-stopenjski lestvico od $» 1=$ Tega nisem delal/a $«$ do $» 4=$ To sem delal/a pogosto $«$ (enako kot pri COPE in EAC). Na dobljenih podatkih smo izvedli komponentno analizo. S testom drobirja smo izločili 7 komponent, ki so skupaj pojasnile $54 \%$ variance postavk in so bile osnova za 7 lestvic. Lastne vrednosti teh 7 komponent in deleži pojasnjene variance po Varimax rotaciji so bili naslednji: $3,6(10,6 \%) ; 2,8(8,2 \%) ; 2,6(7,6$ \%); 2,5 (7,4 \%); 2,3 (6,8 \%); 2,3 (6,6\%); 2,1 (6,3\%). Dve postavki smo zaradi hkratnega uvrščanja v več komponent izločili, tako da je končno število postavk vprašalnika 29. V nadaljevanju navajamo imena lestvic, število postavk za posamezno lestvico, njihove zanesljivosti, ki so za nekatere lestvice precej nizke, in primere postavk (celotni vprašalnik lahko dobite pri avtoricah raziskave): ruminacija (5 postavk; $\alpha=0,85$; primer postavke: $V$ glavi sem si ponavljal/a situacijo, v kateri sva se razšla.); trud za ohranitev zveze (4 postavke; $\alpha=0,73$; primer postavke: Prosil/a sem ga / jo, da ostaneva skupaj.); občutki krivde zaradi razpada zveze ( 3 postavke; $\alpha=0,82$; primer postavke: Za razpad zveze sem krivil/a sebe.); izogibanje, povezano z bivšim partnerjem (5 postavk; $\alpha=0,67$; primer postavke: Izogibal/a sem se krajev, kamor sva pogosto hodila skupaj.); razvajanje sebe (4 postavke; $\alpha=0,67$; primer postavke: Posvečal/a sem se samo stvarem, ki so me veselile.); posredna agresivnost do bivšega partnerja (3 postavke; $\alpha=0,52$; primer postavke: Javno sem poudarjal/a njegove / njene slabosti.); impulzivno iskanje novih partnerjev (4 postavke; $\alpha=0,64$; primer postavke: Zapletal/a sem se v kratke zveze.).

\section{Postopek}

Za zbiranje podatkov smo uporabili metodo »kvazi snežne kepe«. Povezava do spletnega vprašalnika je bila namreč objavljena na socialnih omrežjih ter poslana po elektronski pošti prijateljem in znancem s prošnjo, da povezavo pošljejo naprej svojim prijateljem in znancem. Šest udeležencev je izrazilo željo, da bi vprašalnik izpolnili v tiskani obliki, zato smo jim vprašalnike skupaj s kuverto za odgovor in plačano poštnino poslali po pošti. Sodelovanje v raziskavi je bilo prostovoljno in anonimno. Izpolnjevanje vprašalnikov je trajalo do 30 minut.

\section{Rezultati}

V tabeli 1 so prikazane opisne statistike za dosežke na lestvicah uporabljenih instrumentov in korelacije med dosežki na Vprašalniku posttravmatske rasti in dosežki na lestvicah, ki ocenjujejo načine spoprijemanja s stresom. Ker pri nekaterih lestvicah načinov spoprijemanja $\mathrm{s}$ stresom porazdelitve dosežkov močno odstopajo od normalne porazdelitve, smo v tovrstnih primerih uporabili Spearmanov namesto Pearsonov koeficient korelacije. 
Tabela 1. Opisne statistike dosežkov na lestvicah vseh uporabljenih pripomočkov ter korelacije med načini spoprijemanja in posttravmatsko rastjo

\begin{tabular}{|c|c|c|c|c|c|}
\hline $\begin{array}{l}\text { Vprašalnik } \\
\text { Podlestvica }\end{array}$ & $M$ & $S D$ & Asim. & Spl. & $r$ \\
\hline \multicolumn{6}{|c|}{ Vprašalnik o na čustva usmerjenem spoprijemanju EAC } \\
\hline Predelovanje čustev & 11,2 & 3,2 & $-0,35$ & $-0,57$ & $0,44^{* *}$ \\
\hline Izražanje čustev & 10,4 & 3,3 & $-0,11$ & $-0,86$ & $0,37^{* *}$ \\
\hline \multicolumn{6}{|l|}{ Vprašalnik spoprijemanja COPE } \\
\hline Pozitivna reinterpretacija in rast & 11,7 & 3,0 & $-0,42$ & $-0,59$ & $0,39^{* *}$ \\
\hline Miselna neaktivnost & 9,3 & 2,4 & 0,04 & $-0,19$ & $0,37^{* *}$ \\
\hline Usmerjenost na sprostitev čustev & 9,6 & 3,0 & 0,20 & $-0,71$ & $0,31^{* *}$ \\
\hline Iskanje instrumentalne socialne opore+ & 9,9 & 3,6 & $-0,04$ & $-1,12$ & $0,37^{* *}$ \\
\hline Aktivno spoprijemanje & 8,3 & 2,6 & 0,23 & $-0,58$ & $0,34^{* *}$ \\
\hline Zanikanje+ + & 6,5 & 3,0 & 1,20 & 0,60 & 0,04 \\
\hline Humor+ & 6,5 & 3,0 & 1,14 & 0,51 & $0,16^{*}$ \\
\hline Vedenjska neaktivnost & 7,3 & 2,4 & 0,73 & 0,26 & $0,24^{* *}$ \\
\hline Zadrževanje spontanega odziva & 8,5 & 2,9 & 0,23 & $-0,52$ & $0,29^{* *}$ \\
\hline Iskanje čustvene socialne opore & 11,8 & 3,9 & $-0,54$ & $-0,93$ & $0,38^{* *}$ \\
\hline Uporaba drog in alkohola + & 7,0 & 3,7 & 1,11 & 0,08 & 0,08 \\
\hline Sprejetje & 10,5 & 3,0 & $-0,14$ & $-0,57$ & $0,30^{* *}$ \\
\hline Prekinitev preostalih dejavnosti & 7,0 & 2,7 & 0,75 & $-0,05$ & $0,25^{* *}$ \\
\hline Načrtovanje & 8,6 & 3,0 & 0,14 & $-0,96$ & $0,34^{* *}$ \\
\hline \multicolumn{6}{|c|}{ Vprašalnik spoprijemanja s stresom po razpadu partnerske zveze } \\
\hline Ruminacija & 13,8 & 4,2 & $-0,03$ & $-0,84$ & 0,11 \\
\hline Trud za ohranitev zveze & 5,1 & 2,0 & 2,29 & 5,47 & 0,05 \\
\hline Občutek krivde zaradi razpada zveze & 6,2 & 2,7 & 0,56 & $-0,73$ & 0,08 \\
\hline Izogibanje, povezano $\mathrm{z}$ bivšim partnerjem & 9,2 & 3,5 & 0,68 & $-0,28$ & $0,25^{* *}$ \\
\hline Razvajanje sebe & 9,3 & 2,9 & 0,11 & $-0,70$ & $0,47^{* *}$ \\
\hline Posredna agresivnost do bivšega partnerja & 4,3 & 1,6 & 1,72 & 3,47 & $0,20^{* *}$ \\
\hline Impulzivno iskanje novega partnerja & 6,4 & 2,4 & 1,02 & 0,32 & 0,08 \\
\hline \multicolumn{6}{|l|}{ Vprašalnik posttravmatske rasti PTGI } \\
\hline PTGI & 27,7 & 13,9 & 0,15 & $-0,48$ & \\
\hline
\end{tabular}

Opomba: ${ }^{*} p<0,05,{ }^{* *} p<0,01 ;+$ Spearmanov koeficient korelacije

V vzorcu smo našli zmerne korelacije (nad 0,4) med zaznano posttravmatsko rastjo in pogostostjo rabe dveh načinov spoprijemanja, to sta predelovanje čustev in razvajanje sebe. S posttravmatsko rastjo se nizko do zmerno pozitivno (med 0,3 in 0,4 ) povezujejo še naslednji načini spoprijemanja s stresom: izražanje čustev, pozitivna reinterpretacija in rast, miselna neaktivnost, usmerjenost na sprostitev čustev, aktivno spoprijemanje, iskanje instrumentalne ter čustvene socialne opore, sprejetje in načrtovanje. Korelacije z ostalimi načini spoprijemanja so nižje (pod 0,3$)$. Korelacije so večinoma skladne $\mathrm{z}$ našimi pričakovanji.

Zaradi boljše preglednosti smo v nadaljevanju izvedli komponentno analizo, da bi združili podobne načine spoprijemanja s stresom v nekaj skupin. Tudi avtorji vprašalnika COPE (Carver, Scheier in Weintraub, 1989) ne predpostavljajo vnaprejšnje razvrstitve načinov spoprijemanja $\mathrm{v}$ določene skupine, npr. na problem in na čustva usmerjene, kot sta predlagala Lazarus in Folkman (1984), temveč predlagajo, da se ta razvrstitev naredi za vsak vzorec posebej. Zato smo izvedli komponentno analizo lestvic iz vseh treh vprašalnikov, ki ocenjujejo načine spoprijemanja s stresom. Glede na test drobirja smo izločili šest komponent, ki skupaj pojasnijo 66 $\%$ variance. Lastne vrednosti in pripadajoči deleži pojasnjene variance teh šestih komponent po Varimax rotaciji so naslednje: 3,4 (14,9\%); 3,1 (13,5\%); 2,9 (12,8 $\%) ; 2,6(11,3 \%) ; 1,9(8,1 \%) ; 1,3(5,9 \%)$. V tabeli 2 so prikazane nasičenosti posameznih lestvic z izločenimi komponentami po Varimax rotaciji. S prvo komponento so najbolj nasičene lestvice, ki se nanašajo na usmerjenost na problem, ko posameznik z različnimi načini poskuša odpraviti izvor stresa. $Z$ drugo komponento so nasičeni načini spoprijemanja, ki so usmerjeni na sprostitev oz. izražanje čustev (lahko preko komunikacije z drugimi ljudmi). S tretjo komponento so nasičene lestvice, ki se nanašajo na bolj pasivne načine spoprijemanja, kot je zanikanje ali izogibanje, po drugi strani pa tudi pretirano miselno ukvarjanje s problematiko razpada zveze. Četrta komponenta nasičuje lestvice, ki jih lahko uvrstimo med načine, usmerjene na čustva, vendar gre za konstruktivne načine spoprijemanja. S peto komponento so nasičene 
Tabela 2. Povzetek komponentne analize (nasičenosti za šest glavnih komponent po Varimax rotaciji) lestvic vprašalnikov COPE, EAC in Vprašalnika spoprijemanja s stresom po razpadu partnerske zveze

\begin{tabular}{|c|c|c|c|c|c|c|}
\hline \multirow[b]{2}{*}{ Lestvice } & \multicolumn{6}{|c|}{ Komponente } \\
\hline & 1. & 2. & 3. & 4. & 5. & 6. \\
\hline \multicolumn{7}{|l|}{ 1. Načini, usmerjeni na problem } \\
\hline Načrtovanje & $\mathbf{0 , 8 4}$ & 0,27 & 0,07 & 0,11 & 0,08 & 0,11 \\
\hline Aktivno spoprijemanje & 0,76 & 0,28 & 0,14 & 0,08 & 0,15 & 0,10 \\
\hline Zadrževanje spontanega odziva & $\mathbf{0 , 7 3}$ & 0,08 & 0,10 & 0,31 & 0,02 & 0,00 \\
\hline Prekinitev preostalih dejavnosti & $\mathbf{0 , 7 0}$ & 0,27 & 0,21 & $-0,11$ & 0,20 & 0,02 \\
\hline Predelovanje čustev & $\mathbf{0 , 5 8}$ & 0,40 & $-0,05$ & 0,39 & $-0,19$ & $-0,11$ \\
\hline \multicolumn{7}{|l|}{ 2. Načini, usmerjeni na čustva in druge ljudi } \\
\hline Iskanje čustvene socialne opore & 0,29 & 0,79 & 0,11 & 0,17 & 0,00 & 0,06 \\
\hline Iskanje instrumentalne socialne opore & 0,38 & $\mathbf{0 , 7 3}$ & 0,16 & 0,01 & 0,13 & 0,12 \\
\hline Usmerjenost na sprostitev čustev & 0,24 & 0,69 & 0,42 & $-0,03$ & 0,13 & $-0,10$ \\
\hline Izražanje čustev & 0,37 & 0,66 & 0,00 & 0,30 & $-0,11$ & $-0,02$ \\
\hline \multicolumn{7}{|l|}{ 3. Pasivni in obsesivni načini } \\
\hline Izogibanje, povezano z bivšim partnerjem & 0,00 & 0,05 & $\mathbf{0 , 7 3}$ & 0,29 & 0,02 & 0,04 \\
\hline Občutek krivde zaradi razpada zveze & 0,14 & 0,03 & 0,69 & $-0,15$ & 0,06 & $-0,17$ \\
\hline Zanikanje & 0,01 & 0,13 & 0,69 & $-0,28$ & 0,25 & 0,09 \\
\hline Ruminacija & 0,19 & 0,40 & 0,65 & 0,00 & 0,06 & $-0,31$ \\
\hline Trud za ohranitev zveze & 0,20 & 0,20 & $\mathbf{0 , 5 8}$ & $-0,36$ & 0,20 & 0,14 \\
\hline \multicolumn{7}{|l|}{ 4. Sprejetje in pozitivno samomotiviranje } \\
\hline Sprejetje & 0,11 & 0,00 & $-0,12$ & $\mathbf{0 , 7 8}$ & 0,03 & 0,13 \\
\hline Pozitivna reinterpretacija in rast & 0,36 & 0,08 & $-0,15$ & $\mathbf{0 , 7 0}$ & $-0,12$ & 0,11 \\
\hline Razvajanje sebe & 0,07 & 0,41 & $-0,01$ & 0,63 & 0,25 & 0,05 \\
\hline Miselna neaktivnost & 0,01 & 0,29 & 0,12 & 0,45 & 0,35 & 0,20 \\
\hline \multicolumn{7}{|l|}{ 5. Socialno nesprejemljivi načini } \\
\hline Impulzivno iskanje novega partnerja & 0,08 & $-0,03$ & 0,02 & 0,14 & $\mathbf{0 , 8 1}$ & 0,05 \\
\hline Uporaba alkohola in drog & 0,18 & 0,04 & 0,22 & $-0,04$ & $\mathbf{0 , 7 1}$ & $-0,06$ \\
\hline Posredna agresivnost do bivšega partnerja & $-0,16$ & 0,39 & 0,26 & $-0,06$ & 0,48 & 0,34 \\
\hline \multicolumn{7}{|l|}{ 6. Distanciranje } \\
\hline Humor & 0,11 & 0,02 & $-0,22$ & 0,18 & 0,02 & $\mathbf{0 , 8 3}$ \\
\hline Vedenjska neaktivnost & 0,19 & 0,03 & 0,43 & 0,37 & 0,12 & $\mathbf{0 , 5 0}$ \\
\hline
\end{tabular}

lestvice, ki vključujejo socialno nesprejemljiva vedenja, od zlorabe drog in alkohola, impulzivnega iskanja partnerjev ter posredne agresivnosti. S šesto, najšibkejšo komponento sta nasičeni lestvici humorja in vedenjske neaktivnosti, ki omogočata distanciranje od stresorjev, zato smo to komponento označili kot distanciranje.

Nadalje nas je zanimalo, kolikšen delež variance posttravmatske rasti lahko pojasnijo načini spoprijemanja s stresom, zato smo kot napovednike v multipli regresijski analizi vključili komponentne dosežke, izračunane na podlagi opisane komponentne analize vseh načinov spoprijemanja s stresom. Pri tem smo nadzirali možen vpliv demografskih značilnosti vzorca, zato smo v prvem koraku v regresijsko analizo kot neodvisni spremenljivki vključili spol in starost (z direktno metodo; ang. Enter), $\mathrm{v}$ drugem koraku pa prav tako $\mathrm{z}$ direktno metodo šest $\mathrm{s}$ komponentno analizo prepoznanih načinov spoprijemanja. Iz Tabele 3 lahko razberemo, da spol in starost skupaj pojasnita $4 \%$ variance $\mathrm{v}$ dosežkih posttravmatske rasti. Statistično pomemben napovednik je spol, in sicer ženske poročajo o višji posttravmatski rasti po razpadu zveze. $\mathrm{V}$ drugem koraku smo vključili šest načinov spoprijemanja. Statistično pomembni napovedniki so načini, usmerjeni na problem, načini, usmerjeni na čustva oz. druge ljudi, sprejetje in pozitivno samomotiviranje ter $\mathrm{v}$ manjši meri tudi načini, ki omogočajo distanciranje. Skupaj pojasnjujejo $30 \%$ variance posttravmatske rasti. Pasivni, obsesivni in socialno nesprejemljivi načini se niso izkazali kot pomembni napovedniki posttravmatske rasti.

Rezultati kažejo, da načini spoprijemanja pojasnjujejo pomemben del variance $\mathrm{v}$ posttravmatski rasti, kar je skladno z našimi pričakovanji. Posamezniki, ki pogosteje uporabljajo načine, usmerjene na problem, pa tudi tisti, ki uporabljajo načine, usmerjene na čustva, pa najsi gre zgolj za izražanje oz. sproščanje čustev (v podpornem socialnem okolju ali brez njega) ali pa za spremembo pogleda na situacijo ali zgolj negovanje pozitivnih misli, poročajo o višji posttravmatski rasti. 
Tabela 3. Povzetek hierarhične multiple regresije za napovedovanje posttravmatske rasti na osnovi različnih načinov spoprijemanja s stresom

\begin{tabular}{llrrcc}
\hline Korak & $b$ & $S E_{\mathrm{b}}$ & $\beta$ & $\Delta R^{2}$ \\
\hline 1 & & & & $0,04^{* *}$ \\
& Spol & $-5,88$ & 1,93 & $-0,19^{* *}$ & \\
& Starost & 0,42 & 0,35 & 0,76 & \\
\hline 2 & & & & $0,30^{* *}$ \\
& Spol & $-0,60$ & 1,80 & $-0,02$ & \\
& Starost & 0,04 & 0,30 & 0,01 & \\
Načini, usmerjeni na problem & 3,01 & 0,72 & $0,22^{* *}$ & \\
Načini, usmerjeni na čustva in druge ljudi & 4,45 & 0,75 & $0,32^{* *}$ & \\
& Pasivni in obsesivni načini & 1,35 & 0,72 & 0,10 & \\
& Sprejetje in pozitivno samomotiviranje & 5,42 & 0,75 & $0,39^{* *}$ & \\
& Socialno nesprejemljivi načini & 1,10 & 0,73 & 0,08 & \\
& Distanciranje & 1,58 & 0,72 & $0,11^{*}$ & \\
\hline Skupaj & & & & 0,34 \\
\hline
\end{tabular}

Opomba: ${ }^{*} p<0,05 ;{ }^{* *} p<0,01$.

\section{Razprava}

V raziskavi smo $\mathrm{z}$ vzorcem 260 udeležencev, ki so se v zadnjih dveh letih razšli s svojim partnerjem, proučevali povezanost načinov spoprijemanja s stresom s pozitivnimi spremembami, ki so po mnenju udeležencev posledica razpada zveze. Rezultati so skladni z našimi pričakovanji, da načini spoprijemanja pojasnijo pomemben del variabilnosti $\mathrm{v}$ posttravmatski rasti. $\mathrm{Z}$ njo so povezani tako načini, ki so usmerjeni na problem, kot tudi nekateri načini, ki so usmerjeni na čustva, kar je razumljivo, saj je razpad zveze stresor, ki ga posameznik ne more odstraniti, lahko se predvsem bolj ali manj uspešno spoprijema $\mathrm{z}$ negativnimi čustvi, ki so posledica tega stresnega dogodka.

\section{Skupine načinov spoprijemanja s stresom}

Načini spoprijemanja so po mnenju mnogih raziskovalcev (npr. Folkman in Moskowitz, 2004) osrednji konstrukt, ki določa uspešnost posameznika v prilaganju na okolje. Ker se posameznik neprestano sooča z množico stresorjev, je zanj bistvenega pomena, da jih odstrani, če je to mogoče, oziroma da se čim bolj uspešno spoprime $\mathrm{z}$ negativnimi čustvenimi posledicami teh stresorjev. Uspešnost oz. konstruktivnost posameznih načinov spoprijemanja je odvisna od posamezne situacije, zato ni smiselno vnaprej razvrščati načine $\mathrm{v}$ skupine glede na njihovo učinkovitost, kar opozarjajo tudi avtorji vprašalnika COPE (Carver, Scheier in Weintraub, 1989). Tudi sicer ni konsenza med raziskovalci glede razvrstitve načinov spoprijemanja $\mathrm{v}$ nadredne kategorije (Skinner, Edge, Altman in Sherwood, 2003). V naši raziskavi smo zato sami raziskali odnose med posameznimi načini spoprijemanja $\mathrm{z}$ eksploratorno komponentno analizo. Komponente se deloma prekrivajo stistimi, ki smojih dobili $\mathrm{v}$ raziskavi na vzorcu poklicnih gasilcev (Avsec, Bajec in
Novak, 2012), pri katerih smo uporabili vprašalnika COPE in EAC. Tako kot v prejšnji raziskavi so tudi sedaj načini, usmerjeni na problem, najbolj nasičeni z isto komponento, načini, ki so usmerjeni na izražanje čustev in usmerjenost na druge ljudi, pa z drugo komponento. Zaradi sedmih dodanih načinov spoprijemanja, ki so specifični za razpad zveze, pa se pričakovano ostale štiri komponente razlikujejo glede na omenjeno raziskavo. Pri tretji komponenti težko najdemo vsebinsko podobnost načinov, razen da bi lahko vse označili kot nekonstruktivne. Po eni strani gre za načine, ki omogočajo obvladovanje situacije s približevanjem stresni situaciji, torej v smeri senzitizacije (ruminacija, občutek krivde, trud za ohranitev zveze), po drugi strani pa sta $\mathrm{s}$ to komponento nasičena tudi izogibanje in zanikanje, kar gre za ravno nasprotno strategijo - represijo nasproti senzitizaciji. Čeprav več avtorjev zagovarja splošno delitev načinov spoprijemanja na približevalne in izogibalne (Roth in Cohen, 1986), se na naših podatkih to ni izkazalo, saj so se združevale $\mathrm{v}$ isto komponento. $\mathrm{V}$ nasprotju $\mathrm{s}$ tretjo komponento pa je četrta nasičena s konstruktivnimi načini, ki niso usmerjeni na problem. Gre za načine spoprijemanja, kot je sprejetje, kar je konstruktivno, saj se je zveza že končala, po drugi strani pa razvajanje in miselna neaktivnost omogočata, da obvladamo prvi naval negativnih čustev kot posledico stresne situacije. Da gre za konstruktivne načine, kaže tudi lestvica pozitivna reinterpretacija in rast, ki je predvsem nasičena s to četrto komponento. S peto komponento so nasičeni predvsem načini, ki niso socialno sprejemljivi in so destruktivni za posameznika (impulzivno iskanje novega partnerja, raba alkohola in drog) ali za njegovega bivšega partnerja (posredna agresivnost do bivšega partnerja). S šesto, precej šibko komponento pa sta nasičena predvsem načina humor in vedenjska neaktivnost. Oba omogočata distanciranje od stresorja in zato tudi omogočata drugačen pogled na stresno situacijo. 


\section{Napovedovanje posttravmatske rasti po razpadu partnerske zveze}

Osrednji problem raziskave je bil ugotoviti povezanost med načini spoprijemanja in posttravmatsko rastjo. Ker predhodne raziskave poročajo o razlikah med spoloma v korist žensk pri zaznavanju pozitivnih sprememb (Tashiro in Frazier, 2003; Tedeschi in Calhoun, 1996), smo tudi v naši raziskavi preverili pomen spola in starosti pri napovedovanju posttravmatske rasti. Spol se je izkazal kot pomemben napovednik; posttravmatska rast po razpadu zveze je bolj izrazita pri ženskah, čeprav je velikost učinka majhna. Nekateri avtorji so razliko med spoloma v posttravmatski rasti po razpadu partnerske zveze pojasnjevali z različnimi načini odzivanja moških in žensk stres, torej z rabo različnih načinov spoprijemanja (pregled v Tamres idr., 2002).

$\mathrm{V}$ predhodnih raziskavah dejavnikov posttravmatske rasti so bile izvedene predvsem korelacijske študije, na podlagi katerih smo tudi mi predpostavili nekatere povezave med načini spoprijemanja in posttravmatsko rastjo. Ker se vsebinsko od vseh načinov spoprijemanja $\mathrm{s}$ posttravmatsko rastjo najbolj ujema pozitivna reinterpretacija in rast, ki se nanaša na namenske poskuse najti pozitivne vidike $\mathrm{v}$ stresni situaciji ali njenih izidih, smo v vzorcu po pričakovanjih našli pozitivno povezanost med tem načinom spoprijemanja in posttravmatsko rastjo. Podobne rezultate sta empirično potrdili že Lewandowski in Bizzoco (2007). Način spoprijemanja pozitivna reinterpretacija in rast se skupaj $\mathrm{z}$ načini sprejetje, razvajanje sebe ter miselna neaktivnost povezuje tudi v komponento, ki se vsebinsko nanaša na sprejetje in pozitivno samomotiviranje. Ta je od vseh šestih skupin načinov spoprijemanja najmočnejši napovednik posttravmatske rasti po razpadu partnerske zveze. Povezanost vseh omenjenih načinov in njihova zmožnost napovedovanja rasti po razpadu zveze kaže na to, da so ti načini konstruktivni vsaj $\mathrm{v}$ situaciji spoprijemanja $\mathrm{z}$ razpadom partnerske zveze. To, da posameznik sprejme razpad partnerske zveze kot resničen in dokončen, je pomembno, da začne vlagati energijo $\mathrm{v}$ spoprijemanje $\mathrm{z}$ razpadom namesto $\mathrm{v}$ trud za ohranitev odnosa. Trud za ohranitev odnosa kot način spoprijemanja, npr. moledovanje partnerja, da bi nadaljevala $\mathrm{z}$ odnosom, se $\mathrm{v}$ našem vzorcu ni pomembno povezoval z posttravmatsko rastjo (tabela 1), kar podpira predpostavko, da je sprejetje nujen korak pri uspešnem spoprijemanju $\mathrm{z}$ razpadom partnerske zveze.

Razvajanje sebe in miselna neaktivnost, preostala dva načina $v$ tej skupini, omogočata obvladovanje prvega navala negativnih čustev kot posledico stresne situacije. Razvajanje sebe, ena od lestvic novo-oblikovanega vprašalnika spoprijemanja $\mathrm{s}$ stresom po razpadu partnerske zveze, se nanaša na razmišljanje o svojih pozitivnih lastnostih in vključevanje $\mathrm{v}$ zadovoljujoče aktivnosti, miselna neaktivnost pa na izogibanje razmišljanju o problemu z aktivnostmi, kot so gledanje televizije, sanjarjenje, beg $\mathrm{v}$ spanje, ki so tudi lahko sproščujoče. Vključevanje $\mathrm{v}$ prijetne aktivnosti, pri katerih je posameznik uspešen, deluje kot pozitivna podkrepitev - okrepi njegova občutka lastne vrednosti in kompetentnosti (Berman, Tashiro in Frazier, 2008), ki sta po razpadu zveze lahko močno prizadeta. Okrepljena samozavest in ublažena negativna občutja so dobro izhodišče za nadaljnje uspešno spoprijemanje. Sprejetje razpada partnerske zveze in pozitivno samomotiviranje samega sebe so torej tista vedenja, ki najbolj podpirajo doživljanje pozitivnih sprememb po razpadu partnerske zveze.

Na problem usmerjeni načini spoprijemanja načeloma predstavljajo najbolj konstruktivne načine spoprijemanja, zato smo tudi mi predvidevali njihovo pozitivno povezanost s posttravmatsko rastjo. Tudi predhodne raziskave posttravmatske rasti kažejo, da je ta največja, ko posamezniki uporabljajo aktivne načine spoprijemanja (Dolbier idr., 2010; Schexnaildre, 2011). Skladno s hipotezo smo $\mathrm{v}$ raziskavi potrdili, da so na problem usmerjeni načini spoprijemanja načrtovanje, aktivno spoprijemanje, prekinitev ostalih aktivnosti, zadrževanje spontanega odziva ter predelovanje čustev pomembno pozitivno povezani s posttravmatsko rastjo in da pogostejša raba teh načinov spoprijemanja s stresom pomembno napoveduje večjo posttravmatsko rast. Vsem tem načinom je skupno, da gre za namensko in premišljeno spoprijemanje $\mathrm{z}$ razpadom zveze, tudi s čustvi, ki razpad spremljajo. Povezanost na problem usmerjenih načinov spoprijemanja s predelovanjem čustev kaže, da predelovanje čustev kot način spoprijemanja res opisuje aktivno spoprijemanje s čustvi kot stresorjem - posameznik jih ozavesti, analizira in osmisli. Ob tem procesu prepoznava in / ali spreminja svoje s partnerstvom povezane vrednote in pričakovanja, postavlja nove prioritete glede tega, kaj je pomembno znotraj partnerstva in kako pomembno je zanj partnerstvo samo. Ker se posameznik aktivno spoprijema tako s praktičnimi vidiki izgube partnerstva (npr. izguba zaupnika in intimnega partnerja, skupne rutine, delitev skupne lastnine, »delitev« skupne socialne mreže ipd.) kot tudi s čustveni posledicami razpada, ima občutek avtonomije in nadzora nad svojim življenjem (Litman, 2006). Skupaj pa se to odraža $\mathrm{v}$ zaznavanju pozitivnih sprememb, npr. večje osebne moči in zaznavanjem novih možnosti v življenju, kar je vse del posttravmatske rasti.

Obsežen del spoprijemanja po razpadu partnerske zveze je usmerjen na obvladovanje in uravnavanje negativnih čustvenih odzivov nanj. Sklepali smo, da bodo v kontekstu razpada zveze tudi načini spoprijemanja, usmerjeni na čustva, povezani z zaznavanjem pozitivnih sprememb. Analiza zbranih podatkov kaže, da se sprostitev čustev in izražanje čustev kot načina spoprijemanja pozitivno povezujeta $\mathrm{z}$ doživljanjem pozitivnih sprememb po razpadu zveze. Zavestno uravnavanje lastnega čustvenega odzivanja je torej $\mathrm{v}$ kontekstu spoprijemanja $\mathrm{z}$ razpadlim partnerstvom pojmujemo kot konstruktiven način spoprijemanja, na kar sta opozorila že Austenfeld in Stanton (2004). 
Ker so predhodne raziskave pokazale, da je socialna opora pomembno povezana $\mathrm{s}$ posttravmatsko rastjo (Lewandowski in Bizzoco, 2007), smo predvidevali, da se bodo tudi v našem vzorcu posameznikov po razpadlem partnerstvu socialno podprti načini spoprijemanja pomembno pozitivno povezovali $\mathrm{s}$ posttravmatsko rastjo. Pomembne pozitivne korelacije rasti tako $\mathrm{Z}$ iskanjem čustvene kot instrumentalne socialne opore potrjujejo naše predpostavke. Drugi torej lahko podprejo posameznika pri njegovih poskusih predelave in iskanja pomena negativnega dogodka ter pri osmišljanju čustev, ki spremljajo razpad; mu nudijo novo perspektivo na problem in okrepijo občutek, da je vreden pomoči. Vse to lahko prispeva $\mathrm{k}$ zaznavanju pozitivnih sprememb po razpadu zveze. Usmerjenost na sproščanje in izražanje čustev ter iskanje čustvene in instrumentalne socialne opore se povezujejo tudi v skupni komponenti (imenovani načini, usmerjeni na čustva in druge ljudi), ki pomembno napoveduje posttravmatsko rast. Ko posameznik izraža svoja na razpad partnerske zveze vezana neprijetna čustva v varnem, sprejemajočem socialnem kontekstu, ga drugi podprejo pri njegovih poskusih osmišljanja razpada in spremljajočih čustev. Verjetno posameznik šele ob verbalizaciji svojih misli in občutij drugim ljudem svoje doživljanje dokončno ozavesti in oceni njegovo ustreznost in (ne)koristnost. Drugi lahko ponudijo novo perspektivo na razpad zveze ali partnerstvo na splošno in svetujejo, kako naj se posameznik uspešneje spoprime $\mathrm{z}$ razpadom zveze. Že sama prisotnost drugih in njihova podpora pa krepijo občutek, da je posameznik vreden pozornosti, naklonjenosti in pomoči. Očitno je torej, da je izražanje čustev ob ustrezni socialni opori eden ključnih dejavnikov, ki omogočajo posttravmatsko rast po razpadu partnerske zveze.

Distanciranje je zadnja, najšibkejša komponenta, ki smo jo dobili pri komponentni analizi vseh načinov spoprijemanja. Sestavljena je iz rabe humorja in vedenjske neaktivnosti, ki sicer posttravmatsko rast po razpadu zveze napoveduje statistično pomembno, a je napovedna vrednost nizka, skorajda zanemarljiva. Načina spoprijemanja omogočata odmik od stresorja in drugačen pogled nanj, zato ta komponenta pomembno napoveduje posttravmatsko rast. Vseeno pa so ta vedenja ne predstavljajo niti aktivnega predelovanja razpada in čustev niti ne zagotavljajo ustreznih pozitivnih potrditev.

Komponenti, ki ne napovedujeta rasti, pa vključujeta pasivne in obsesivne ter socialno nesprejemljive načine spoprijemanja. Socialno nesprejemljivi načini so skupina načinov, ki jim je skupna predvsem destruktivnost do sebe ali bivšega partnerja: nepremišljeno, naglo iskanje novih partnerjev in zbujanje pozornosti pri potencialnih partnerjih (impulzivno iskanje novega partnerja), raba alkohola in drog ter posredna agresivnost do bivšega partnerja, izražena $\mathrm{s}$ poskusi škodovanja bivšemu partnerju s sprožanjem govoric, izdajanjem skrivnosti in podobno. Glede na to, da ti načini ne napovedujejo posttravmatske rasti, jih lahko razumemo kot manj adaptivne načine, kar je razvidno že iz njihove vsebine.
$\mathrm{S}$ takim vedenjem se posameznik ne spoprime ne $\mathrm{z}$ virom problema ne s čustvi, ki so s tem povezani, in - vsaj na daljši rok - pri tem ne dobi nikakršne potrditve. Deloma bi lahko potrditev pomenila uspešnost pri iskanju novega partnerja, a je vprašanje, če lahko kratkotrajni odnosi z neznanci prispevajo $\mathrm{k}$ globalnemu boljšemu počutju in okrepljenemu občutku lastne vrednosti, ki je bil okrnjen ob razpadu (Perriloux in Buss, 2008); novega intimnega in zadovoljujočega partnerstva pa $\mathrm{v}$ prvem mesecu po razpadu udeleženci verjetno niso vzpostavili. Tudi raba alkohola in drog lahko »otopi« negativna čustva, a seveda le za krajši čas, hkrati pa niso zaradi tega čustva nič bolj razumljena in predelana. Prek sovražnosti do bivšega partnerja, ki je z rastjo pomembno, a nizko povezan način spoprijemanja (tabela 1), morda posameznik sprosti nekaj negativnih občutkov, a tudi to očitno ne predstavlja posebej učinkovite rešitve problema.

Komponenta, ki smo jo poimenovali pasivni in obsesivni načini spoprijemanja, je skupek naslednjih načinov spoprijemanja, ki kot skupina ne napovedujejo rasti po razpadu zveze: izogibanje, povezano $\mathrm{z}$ bivšim partnerjem, občutki krivde zaradi razpada zveze, zanikanje, ruminacija ter trud za ohranitev zveze. Mnogi avtorji tudi odziv na izgubo partnerja zaradi razpada zveze (in ne le zaradi smrti) opredelijo kot žalovanje (npr. Boelen in van der Hout, 2010). Nekatera prej opisana vedenja (zanikanje ali nezmožnost dojeti, da je izguba bolj ali manj dokončna in resnična, nenamensko ruminativno razmišljanje o partnerju, zvezi in njenem razpadu) z vidika pričetka žalovanja po izgubi niso nepričakovan odziv, a ovirajo in odlagajo soočanje $z$ dejstvom, da je partnerske zveze konec. Pričakovano je torej bilo, da ti načini niso pozitivno povezani $\mathrm{z}$ doživljanjem posttravmatske rasti po razpadu.

Edini od načinov spoprijemanja $\mathrm{v}$ tej skupini, ki se samostojno pomembno, a nizko pozitivno povezuje $\mathrm{s}$ posttravmatsko rastjo, je izogibanje, povezano z bivšim partnerjem, krajem in predmetom, ki so povezani z zvezo ali razpadom. V skladu $\mathrm{z}$ našimi rezultati je npr. raziskava (Sbarra in Emery, 2005), v kateri so udeleženci poročali o bolj izraženi žalosti v tistih dnevih, ko so imeli stik z bivšim partnerjem. Izogibanje opomnikom na zvezo je torej lahko način izogibanja virom negativnih občutij, pa najsi bo to kraj, predmet ali oseba, npr. skupni prijatelj, s katerim so povezani spomini na partnersko zvezo in bi lahko sprožili negativna občutja. Smiselno je torej, da je izogibanje situacijam, ki bi še dodatno spodbudile negativno čustvovanje in razmišljanje, pozitivno povezano $\mathrm{z}$ rastjo.

\section{Zaključki}

V raziskavi smo se ukvarjali s povezanostjo načinov spoprijemanja s stresom po razpadu partnerstva mladih na prehodu v odraslost s posttravmatsko rastjo kot posledico tega razpada. Načine spoprijemanja, ki prispevajo $\mathrm{k}$ pozitivnim izidom, smo skušali prepoznati predvsem zato, da lahko posameznike, ki se ravno spoprijemajo $\mathrm{z}$ 
razpadom partnerstva, spodbudimo $\mathrm{k}$ spoprijemanju na načine, kipodpirajopozitivnespremembe. Rezultatikažejo, da posttravmatsko rast napovedujejo naslednji načini spoprijemanja: sprejetje in pozitivno samomotiviranje, načini, usmerjeni na problem ter načini, usmerjeni na čustva in druge ljudi. Posameznik, ki sprejme, da je zveze konec in namensko skuša najti pozitivne vidike tega, se posveča zadovoljujočim aktivnostim, izraža svoja čustva in je pri tem $v$ podpirajočem socialnem okolju in se $z$ razpadom in svojimi čustvi spoprijema aktivno, bo doživel več pozitivnih sprememb.

$\mathrm{Ob}$ teh ugotovitvah je potrebno opozoriti na nekatere pomanjkljivosti raziskave. Ker je bil vzorec v naši raziskavi starostno omejen na obdobje prehoda $\mathrm{V}$ odraslost, bi veljalo načine spoprijemanja $\mathrm{z}$ razpadom partnerstva in doživljanje posttravmatske rasti ob tem preveriti tudi pri mladostnikih, ki tudi že oblikujejo partnerske zveze, pa tudi pri odraslih, ki so predvidoma $\mathrm{v}$ partnerstvu že bolj izkušeni. Zaželeno bi bilo vzorec tudi uravnotežiti po spolu, saj v našem vzorcu prevladujejo ženske. Pomanjkljivost raziskave je tudi v tem, da so udeleženci o načinih spoprijemanja, ki so jih uporabljali v prvem mesecu po razpadu, poročali retrospektivno. Kljub omejitvi, da se je razpad zveze zgodil največ dve leti pred sodelovanjem $\mathrm{v}$ raziskavi, je seveda možno, da je bilo poročanje o oddaljenem stresnem dogodku podvrženo raznim izkrivljanjem. V nadaljnjih raziskavah bi bilo zato smiselno preverjati tudi kvaliteto partnerskega odnosa, preden se je končal, morda tudi vpliv stilov navezanosti na odziv na razpad in na izbiro načinov spoprijemanja. Vse to bi lahko najbolje preverjali z vzdolžno raziskavo, v kateri bi pare spremljali še pred razpadom in pri morebitnih razpadlih zvezah preučili spoprijemanje in posttravmatsko rast ter kako se zaznane pozitivne spremembe po razpadu ene zveze povezujejo $\mathrm{z}$ zadovoljstvom $\mathrm{z}$ naslednjo partnersko zvezo.

V kontekstu spoprijemanja s stresom po razpadli zvezi bi lahko kot spremenljivko, ki verjetno vpliva na spoprijemanje in njegov izid, vključili tudi podatek o tem, kolikokrat so posamezniki že prekinili relativno stabilno in trajno partnersko zvezo.

Vzdolžno bi lahko preučevali tudi sam časovni vidik rabe načinov spoprijemanja $z$ razpadom zveze. $V$ naši raziskavi smo se osredotočili le na spoprijemanje v prvem mesecu po razpadu, zagotovo pa pri večini posameznikih traja dlje, da dokončno predelajo razpad, nekateri, ki so zvezo prekinili samoiniciativno, pa so morda izgubo »odžalovali« že prej, preden so o svoji odločitvi o prekinitvi odnosa »obvestili« svojega partnerja.

\section{Literatura}

Arnett, J. J. (2000). Emerging adulthood: A theory of development from the late teens through twenties. American Psychologist, 55(5), 469-480.

Austenfeld, J. L. in Stanton, A. L. (2004). Coping through emotional approach: A new look at emotion, coping, and health-related outcomes. Journal of Personality, 72, 1335-1364.
Avsec, A., Bajec, B. in Novak, M. (2012). Differential relationship of coping styles with well-being and ill-being of professional firemen. Psihologija, 45(1), 59-70.

Battaglia, D. M., Richard, F. D., Datteri, D. L. in Lord, C. G. (1998). Breaking up is (relatively) easy to do: A script for the dissolution of close relationships. Journal of Social and Personal Relationships, 15, 829-845.

Benton, S., Robertson, J. M., Tseng, W. C., Newton, F. B. in Benton, S. L. (2003). Changes in client problems: Contributions and limitations from a 13-year study. Professional Psychology: Research and Practice, 34, 66-72.

Berman, M. I., Tashiro, T. in Frazier, P. A. (2008). Personal growth after relationship breakups. V S. J. Lopez (ur.), Positive Psychology: Exploring the Best in People (str. 29-48). Westport: Praeger.

Boelen, P. A. in van den Hout, M. A. (2010). Inclusion of other in the self and breakup-related grief following relationship dissolution. Journal of Loss and Trauma: International Perspectives on Stress \& Coping, 15(6), 534-547.

Calhoun, L. G., Cann, A., Tedeschi, R. G. in McMillan, J. (2000). A correlational test of the relationship between posttraumatic growth, religion and cognitive processing. Journal of Posttraumatic Stress, 13(3), 521-527.

Carver, C. S., Scheier, M. F. in Weintraub, J. K. (1989). Assessing coping strategies: A theoretically based approach. Journal of Personality and Social Psychology, 56(2), 267-283.

Choo, P., Levine, T. in Hatfield, E. (1996). Gender, love schemas, and reactions to romantic break-ups. Journal of Social Behavior and Personality, 11, 143-160.

Dolbier, C. L., Smith Jaggars, S. in Steinhardt, M. A. (2010). Stress-related growth: Pre-intervention correlates and change following a resilience intervention. Stress and Health, 26, 135-147.

Drigotas, S. M. in Rusbult, S. E. (1992). Should I stay or should I go? A dependence model of breakups. Journal of Personality and Social Psychology, 62, 62-87.

Folkman, S. in Moskowitz, J. T. (2004). Coping: Pitfalls and promise. Annual Review of Psychology, 55, 745-774.

Graff-Reed, R. L. (2004). Positive effects of stressful life events: Psychological growth following divorce. Neobjavljeno doktorsko delo, Miami University, Oxford, OH, ZDA.

Hebert, S. (2006). »Where do I go from here? « A grounded theory of distress, change, and personal growth following the dissolution of non-marital romantic relationship. Magistrsko delo na Simon Fraser University, pridobljeno 21. 5. 2011 s spletne strani http://ir.lib.sfu.ca/retrieve/4198/etd2615.pdf

Joseph, S. in Linley, A. P. (2008). Trauma, recovery and growth. Positive psychological perspectives on posttraumatic stress. Hoboken: Wiley. 
Lazarus, R. S., in Folkman, S. (1984). Stress, appraisal, and coping. New York, NY: Springer.

Lewandowski, G. W. in Bizzoco, N. M. (2007). Addition through subtraction: Growth following the dissolution of a low quality relationship. The Journal of Positive Psychology, 2, 40-54.

Linley, P. A. in Joseph, S. (2009). Posttraumatic growth. V S. J. Lopez (ur.), The encyclopedia of positive psychology (str. 769-773), Chichester; Malden: Wiley-Blackwell.

Litman, J. A. (2006). The COPE inventory: Dimensionality and relationships with approach- and avoidancemotives and positive and negative traits. Personality and Individual Differences, 41, 273-284.

Monroe, S. M., Rohde, P., Seeley, J. R. in Lewinsohn, P. M. (1999). Life events and depression in adolescence: Relationship loss as a risk factor for first onset of major depressive disorder. Journal of Abnormal Psychology, 108, 606-614.

Morris, B. A., Shakespeare-Finch, J. in Scott, J. L. (2007). Coping processes and dimensions of posttraumatic growth. The Australasian Journal of Disaster and Trauma Studies, 1, objavljen na http://www.massey. ac.nz/ trauma/issues/2007-1/morris.htm

Perilloux, C. in Buss, D. M. (2008). Breaking up romantic relationships: Cost experienced and coping strategies deployed. Evolutionary Psychology, 6, 164-181.

Plutchik, R. (2002). Emotions and life: Perspectives from psychology, biology, and evolution. Washington, DC: American Psychological Association.

Reevy, G. (2007). Sex-related differences in the social support-stress relationship. V A. Monat, R. S. Lazarus in G. Reevy (ur.), The Praeger handbook on stress and coping (volume 2) (str. 349-359). Westport: Praeger.

Rhoades, G. K., Kamp Dush, C. M., Atkins, D. C., Stanley, S. M. in Markman, H. J. (2011). Breaking up is hard to do: The impact of unmarried relationship dissolution on mental health and life satisfaction. Journal of Family Psychology, 25, 366-374.

Roth, S. in Cohen, L. J. (1986). Approach, avoidance, and coping with stress. American Psychologist, 41, 813-819.

Sbarra, D. A. in Emery, R. E. (2005). The emotional sequel of nonmarital relationship dissolution: Analysis of change and intraindividual variability over time. Personal Relationships, 12, 213-232.

Schexnaildre, M. A. (2011). Predicting posttraumatic growth: Coping, social support, and posttraumatic stress in children and adolescents after hurricane Katrina. Doktorsko delo, objavljeno na http:/etd. lsu.edu/docs/available/etd-04022011-221554/ unrestricted/SchexnaildreThesis.pdf

Simon, R. W. in Barrett, A. E. (2010). Nonmarital romantic relationships and mental health in early adulthood: Does the association differ for women and men? Journal of Health and Social Behavior, 51, 168-182.
Simpson, J. A. (1987). The dissolution of romantic relationships: Factors involved in relationship stability and emotional distress. Journal of Personality and Social Psychology, 53, 683-692.

Skinner, E., Edge, K., Altman, J. in Sherwood, H. (2003). Searching for the structure of coping: A review and critique of category systems for classifying ways of coping. Psychological Bulletin, 129, 216-269.

Stanton, A. L., Kirk, S. B., Cameron, C. L. in Danoff-Burg, S. (2000). Coping through emotional approach: Scale construction and validation. Journal of Personality and Social Psychology, 78, 1150-1169.

Tamres, L. K., Janicki, D. in Helgeson, V. S. (2002). Sex differences in coping behavior: A meta-analytic review and an examination of relative coping. Personality and Social Psychology Review, 6, 2-30.

Tashiro, T. in Frazier, P. (2003). »I'll never be in a relationship like that again«: Personal growth following romantic relationship breakups. Personal Relationships, 10, 113-128.

Tashiro, T., Frazier, P. in Berman, M. (2006). Stress-related growth following divorce and relationship dissolution. V M. A. Fine, in J. H. Harvey (ur.), Handbook of divorce and relationship dissolution (str. 361-384). Mahwah, NJ, ZDA: Lawrence Erlbaum and Associates.

Tedeschi, R. G. in Calhoun, L. G. (1996). The posttraumatic growth inventory: Measuring the positive legacy of trauma. Journal of Posttraumatic Stress, 9, 455-471.

Tedeschi, R. G. in Calhoun, L. G. (2004). Posttraumatic growth: Conceptual foundations and empirical evidence. Psychological Inquiry, 15, 1-18.

Wyder, M., Ward, P. in De Leo, D. (2009). Separation as a suicide risk factor. Journal of Affective Disorders, 116, 208-213.

Zupančič, M. (2004). Opredelitev razvojnega obdobja in razvojne naloge v mladostništvu. V L. Marjanovič Umek in M. Zupančič (ur.), Razvojna psihologija (str. 511-524). Ljubljana: Znanstveni Inštitut Filozofske Fakultete. 